\title{
ZAGZEBSKI ON RATIONALITY
}

\section{DUNCAN PRITCHARD \& SHANE RYAN}

\author{
University of Edinburgh Soochow University, Taipei
}

\section{INTRODUCTION ${ }^{1}$}

This paper examines Linda Zagzebski’s (2012) account of rationality, as set out in her rich, wide-ranging, and important book, Epistemic Authority: A Theory of Trust, Authority, and Autonomy in Belief. We briefly describe the account that she offers and then consider its plausibility. In particular, in the first section we argue that a number of Zagzebski's claims with regard to rationality require more support than she offers for them. Moreover, in the second section, we contend that far from offering Zagzebski a quick way of dealing with radical scepticism, her account of rationality actually seems to be particularly vulnerable to this problem.

\section{ZAGZEBSKI ON RATIONALITY}

For Zagzebski (2012: 30), 'rationality is a property we have when we do what we do naturally, only we do a better job of it', while being rational 'is to do a better job of what we do in any case, what our faculties do naturally'. Zagzebski is considering rationality in a broad sense of the term, a sense related in a certain way to the relationship between aspects of the self, for example, beliefs and desires. In arguing that a standard of rationality is provided by how a self naturally operates, Zagzebski (2012: 33) writes that 'there is a connection between the natural and the normative, in particular, a connection between the self as it naturally operates and the way it should operate. Zagzebski thus holds that the kind of performance that allows us to be rational is guided normatively by how we operate naturally. ${ }^{2}$

${ }^{1}$ We are grateful to an anonymous reviewer from the journal for detailed comments on an earlier version of this paper. Thanks also to Marcin Iwanicki and Linda Zagzebski.

2 Note that Zagzebski (e.g., 2012: 30-31) sometimes uses 'automatically' and 'unconsciously' as synonyms for 'naturally'. 
Zagzebski (2012: 29) notes that '[b]eliefs, emotions, desires, and decisions can conflict with one another'. When there are such conflicts, we may experience dissonance. In fact, the experience of dissonance is a way we have of detecting such conflict. Although for Zagzebski (2012: 31 ) in some cases we can get on fine without resolving dissonance, it's better if dissonance is resolved. Indeed, for Zagzebski a harmonious self is something we desire and attempt to achieve by our nature. Relatedly, Zagzebski argues that we also have a natural desire for the truth. ${ }^{3}$ Conflicts can sometimes be resolved unconsciously or naturally. For example, you may believe that you have turned off your alarm clock, but then you hear the alarm going off. You unconsciously give up your belief that you have turned off the alarm clock. Sometimes, however, dissonance caused by conflict is not resolved in this way.

Aside from writing that being rational is doing a better job of what we do naturally, Zagzebski (2012: 217) specifically holds that resolving detected conflict in the self that one is aware of is part of being rational. This may involve, for example, the targeting of a belief to be given up in the face of a conflict between beliefs. She writes that when we engage in such targeting, we should ask ourselves which belief is most likely to withstand future self-reflection. So to be rational is to do a better job than what we do automatically, it requires resolving conflict in a way that we judge will survive future self-reflection, and it is better to resolve conflict given our natural desire for a harmonious self. It follows that an agent who, for example, resolves a conflict in their beliefs in a nonautomatic way, and does so in a way which she judges will survive future reflection, is being rational. ${ }^{4}$ For Zagzebski (2012: 231), although what we judge will survive future reflection might turn out to be wrong, there is a connection between our judgements of what will survive future reflection and the truth of what will survive future reflection.

Rationality is good because having such rationality means being better placed to have the harmony of self that we naturally desire and

3 Zagzebski sees this particular natural desire as part of the pre-reflective self. Interestingly, it is common these days for epistemologists to claim that truth is not even a fundamental epistemic good (i.e., something which is good along a specifically epistemic axis of evaluation), let alone a value that we naturally desire. See Pritchard (2014b) for a recent discussion of some of the issues in this regard.

${ }^{4}$ Note that any such resolution of conflict would have to come about in an appropriate way; e.g., it would have to have to have the right aetiology. 
naturally seek to achieve. There is a sense in which Zagzebski's claims about our nature being such, and about nature being a marker for the normative, leads to our conscious selves being required to be a certain way normatively. ${ }^{5}$ Not only are we not being rational if we don't respond to detected conflict in the way that Zagzebski outlines, but we're also failing in a normative sense.

How plausible is Zagzebski's view of rationality? Why should we think that the natural is a guide to the normative? Zagzebski sets these positions out rather than providing a full account of rationality. Perhaps one thought here might be that we are naturally well-functioning, so when we come to consider how we should be in various domains, how we are pre-reflectively or unconsciously provides some initial guidance. ${ }^{6}$ And while there may be some cases in which how we are naturally or what we do unconsciously should not be taken as providing normative guidance, for example our natural thinking with regard to probabilities, we might think such cases are the exception rather than the rule.

There are a number of empirical issues raised by Zagzebski's claims, perhaps the most fundamental of which includes whether humans naturally resolve or try to resolve conflicts between different parts of the self. One might wonder whether this is what we naturally do or whether something else, such as suppression of conflict in the self, is usual. ${ }^{7}$ In fact, it seems plausible that frequently we don't naturally do anything about conflicts in the self; an agent gains a new belief that conflicts with an old one, or a belief that conflicts with a desire, and the self doesn't naturally do anything about the conflict. If it turns out that we don't typically naturally resolve conflicts in the self, or even naturally attempt to solve such conflicts, and we accept Zagzebski's (2012: 32-33) claim that how the self operates naturally with regard to conflict in the self serves as a standard for rationality, then why should we think that it is rational to resolve conflicts in the self? It would be good, therefore, to

\footnotetext{
${ }^{5}$ Interestingly, the requirement that we resolve any conflict by judging what will best withstand future self-reflection is a way of promoting diachronic self-harmony.

${ }^{6}$ Alternative thoughts might be that Zagzebski's positions enjoy intuitive plausibility, or that, given that they together with what she has to say about epistemic authority provide us with interesting and plausible answers on the topic of epistemic authority, it makes sense theoretically to adopt these positions.

7 Zagzebski (2012: 30) mentions that the self may sometimes attempt to resolve conflict by suppressing the feeling of dissonance, which is a somewhat different claim.
} 
have empirical evidence that supports the characterisation that naturally we resolve conflicts in the self. ${ }^{8}$

Even if it turns out that natural resolution of conflict in the self, or its attempt, is typical, it's not clear on what basis Zagzebski can appeal to only those cases and not other cases in which we operate naturally with regard to conflict in the self. She writes of there being a connection between the natural and the normative, but we need a basis for distinguishing between different natural operations, as presumably Zagzebski doesn't want to offer all natural operations with regard to conflict in the self as a standard for the rational, but only some. Perhaps she might support favouring the resolving of conflicts in the self over other natural operations by appeal to what she claims is our natural desire for harmony in the self.

Whether we have natural desires again is an empirical claim. Given that, as Zagzebski (2012: 33-34) acknowledges, philosophers in recent times generally don't claim that we have such desires, the dialectical burden is on her to give us some reason to think that there are such desires. ${ }^{9}$ Furthermore, even if we do have basic desires, such as a nonreflective desire for truth and a desire for harmony in the self, it's not obvious that their origin is in the natural. Automatic or unconscious behaviour needn't have its source in nature. Some of what Zagzebski attributes to the natural may be non-natural, say, cultural in origin. It may even be the case that the societies that survive are ones that, say, place a high value on truth, and so there is universal or near universal acceptance of the value of truth. ${ }^{10}$ It would be good to have a more detailed account of natural desires, including empirical evidence that we do desire what Zagzebski claims we desire and that those desires are natural desires, especially given the role the natural as a standard for the normative has on Zagzebski's account.

A possible nearby alternative to Zagzebski's view that we have the natural desires that she describes is that we are naturally desirous of

\footnotetext{
${ }^{8}$ Longworth (2013: 159) also notes the lack of empirical evidence for claims made by Zagzebski about the natural.

${ }^{9}$ Longworth (2014: 161) makes a similar point, writing that it would be good if Zagzebski offered some reason to think that contemporary philosophers do or should accept that there are natural desires. Zagzebski (2012:33-34) does write that traditionally there has been discussion of natural desires in philosophy and that reference to natural desires is common in other disciplines, though it's fair to say that this falls short of giving us a reason to think that there are such desires.

${ }^{10}$ Or it may simply be the case that some cultures don't place a high value on truth and that there is not a universal or near universal desire for truth.
} 
evolutionary success (i.e., we desire to survive and prosper, for our kin to survive and prosper, to successfully reproduce, and so on). A desire for evolutionary success may propagate derivative desires the fulfilment of which are instrumental to evolutionary success. Such examples may include being able to get food, form social bonds, navigate social hierarchies, and so forth. A desire for such successes may often happen to lead us to getting truths and behaving in consistent ways. The view presented here could explain much of the initial intuitive pull of the thought that we have a natural desire for truth and a natural desire for harmony. Given that this possible nearby alternative seems relatively obvious and at least as plausible as the natural desires that Zagzebski describes, it's an alternative that defenders of the view that we have the natural desires that Zagzebski describes should rule out. ${ }^{11}$

Even if what Zagzebski attributes to the natural is indeed natural with regard to us resolving conflict within the self and having the desires she describes, we have good reason to question that the natural can be a good guide to the normative. Presumably the way we naturally form beliefs, naturally respond to conflicts within the self, and the natural desires we have, are best explained as part of an evolutionary story. As such it would be odd to think that, for example, the way we've happened to evolve to respond to conflicts in the self is connected to how we should respond to such conflicts. After all, what we naturally do in these respects presumably is a product of what has been evolutionarily advantageous, but what is evolutionarily advantageous doesn't obviously coincide with what we have thought of as, say, epistemically normative. Furthermore, any story where the natural provides a guiding role to the normative in ways that go beyond saying roughly that we should promote the survival of our genes looks committed in principle to relativism. After all, natures other than our own are theoretically possible, there may be alien species that even have such natures. If nature is a standard for the normative, and if there can be several natures, then there can presumably be several normative standards, for example in the ethical domain or the epistemic domain. While this isn't obviously wrong, it's a consequence of Zagzebski's stance that warrants consideration.

${ }^{11}$ Alternatively, such defenders may claim that though there may be much overlap between the two sets of desires, we naturally have both sets of natural desires. 


\section{ZAGZEBSKI ON RATIONALITY: RADICAL SCEPTICISM}

Zagzebski appeals to her view of rationality in order to offer a quick dismissal of the problem of radical scepticism. Roughly, her claim is that since rationality is doing a better job of what we do naturally, it follows that radical scepticism cannot be rational since it is not natural. (Zagzebski 2012: 45) While undoubtedly appealing, we do not believe that this approach to radical scepticism stands up to closer scrutiny.

The first point to note about this way of dealing with radical scepticism is that it confuses the problem of radical scepticism with the radical sceptical position, where the latter is a philosophical stance which embraces the radical sceptical conclusion. As many commentators in the contemporary debate about radical scepticism have noted - most notably Barry Stroud (1984) - it is very important to keep these two ways of thinking about radical scepticism apart. Part of the reason for this relates to the very point that Zagzebski makes, which is that we know in advance that the sceptical position is untenable in various ways - for example, we know that it would lead to cognitive paralysis and that it is almost certainly psychologically impossible. ${ }^{12}$

Merely noting the implausibility of the radical sceptical stance doesn't in itself offer us any intellectual comfort when it comes to resolving the radical sceptical problem, however, since the challenge posed by this problem doesn't in any way trade upon whether being an actual radical sceptic is a viable theoretical option. Indeed, the sceptical problem is best thought of as a putative paradox - viz., a series of claims which are highly intuitive when taken individually, and which on the face of it are rooted in our ordinary epistemological commitments, but which collectively generate a contradiction. Radical scepticism qua position is then one particularly dramatic way of resolving this paradox, but the point is that any resolution will involve denying something intuitive (or else demonstrating that it is not as intuitive as we initially supposed). ${ }^{13}$

${ }^{12}$ Note that, like Zagzebski (though see note 13), we are specifically talking about radical scepticism here. In particular, there may be more moderate forms of scepticism (some varieties of Pyrrhonian scepticism, for example) about which this doesn't apply. For the claim that radical scepticism leads to cognitive paralysis, see, e.g., Wright (2004). For the claim that radical sceptical doubt is psychologically impossible, see Strawson (1985).

${ }^{13}$ Part of the reason why Zagzebski fails to notice this point could be her tendency to treat Pyrrhonian scepticism as representative for radical scepticism more generally, even while discussing features of the radical sceptical problem (such as the problem of epistemic circularity) which aren't essentially allied to the Pyrrhonian stance. Pyrrhonian scepticism - even in its most radical guise (see note 12) - is unusual, however, in that it 
Note also that, as Stroud (1984) famously argued, radical scepticism $q u a$ paradox can be rooted in our everyday - and thus 'natural', by Zagzebski's lights - epistemological commitments and yet nonetheless consist of a kind of epistemic evaluation which is very different from our ordinary practices. The point is that the sceptical system of epistemic evaluation is meant to be a purified version of our everyday practices, one that abstracts away from irrelevant limitations of time, imagination, thoroughness, and so on. In this way, it can both be true that radical scepticism is rooted in our everyday epistemological commitments and that, for example - see Zagzebski (2012: 36) - we naturally trust our faculties to lead us to the truth. ${ }^{14}$

Imagine, if you will, that we follow our natural desire for the truth that Zagzebski outlines, but do so unfettered by purely practical concerns. The problem posed by radical scepticism is that we seem thereby to be led to a position according to which knowledge is almost impossible to obtain. Radical scepticism thus falls out of a perfectly natural way of reasoning. In particular, we are led to radical scepticism by doing what we naturally do on this score, albeit in a more thorough and exacting way. Since, for Zagzebski, the hallmark of rationality is to do what we naturally do, albeit in a better way, then it seems that the radical sceptical paradox is not the result of irrational ways of thinking, but rather a by-product of a view of rationality which, as in Zagzebski's account, is rooted in the natural.

The upshot is that Zagzebski's account of rationality does not offer the quick resolution of the problem of radical scepticism that she supposes. In fact, her account of rationality seems particularly vulnerable to this very problem. ${ }^{15}$

is an explicitly embodied form of radical doubt. It thus tends to obscure the distinction between radical scepticism qua position and qua paradox.

${ }^{14}$ Indeed, it is no part of radical scepticism on this construal to dispute that it is natural to trust our faculties. The point is rather that this trust is incompatible with some of our other natural epistemological commitments, such that something is amiss somewhere - that's more than enough to motivate radical scepticism, it does not need to be further added where our intellectual mistake lies. For further discussion of the very idea of radical scepticism qua paradox, see Pritchard (2014a; forthcoming, part one).

15 Zagzebski (2012: 30-31) notes that some paradoxes - she mentions the Lottery Paradox and the Preface Paradox in this regard - are such that they don't provoke an experience of dissonance. Instead, we treat them as 'intellectual puzzles'. Perhaps radical scepticism qua paradox is of this kind (Hume famously thought so). But note that this doesn't mean that such paradoxes are intellectually idle. As epistemologists, we need to understand what is generating the paradox and thereby determine the means to resolve it, even if the paradox has no sway over our day-to-day intellectual lives. 


\section{BIBLIOGRAPHY}

Baril, A. 2013. 'Review of Epistemic Authority: A Theory of Trust, Authority, and Autonomy in Belief, Notre Dame Philosophical Reviews, available at: <http:// ndpr.nd.edu/news/41479-epistemic-authority-a-theory-of-trust-authorityand-autonomy-in-belief/> [accessed 28/11/14]

Longworth, G. 2014. 'Epistemic Authority', Analysis, 74: 157-166

Pritchard, D. H. 2014a. 'Sceptical Intuitions', in Intuitions, D. Rowbottom \& T. Booth (eds.) (Oxford: Oxford University Press), pp. 213-31

Pritchard, D. H. 2014b. 'Truth as the Fundamental Epistemic Good', in The Ethics of Belief: Individual and Social, J. Matheson \& R. Vitz (eds.) (Oxford: Oxford University Press), pp. 112-29

Pritchard, D. H. Forthcoming. Epistemic Angst: Radical Skepticism and the Groundlessness of Our Believing (Princeton, NJ: Princeton University Press)

Strawson, P. F. 1985. Skepticism and Naturalism: Some Varieties (New York: Columbia University Press)

Stroud, B. 1984. The Significance of Philosophical Scepticism (Oxford: Clarendon Press)

Wright, C. J. G. 2004. 'Hinge Propositions and the Serenity Prayer', in Knowledge and Belief, W. Loffler \& P. Weingartner (eds.) (Vienna: Holder-PicklerTempsky), pp. 287-306

Zagzebski, L. T. 2012. Epistemic Authority: A Theory of Trust, Authority, and Autonomy in Belief (Oxford: Oxford University Press) 